\title{
Management of childhood-onset autoinflammatory diseases during the COVID-19 pandemic
}

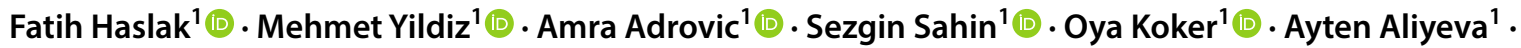 \\ Kenan Barut ${ }^{1}{ }^{1} \cdot$ Ozgur Kasapcopur $^{1}{ }^{1}$
}

Received: 30 May 2020 / Accepted: 3 July 2020 / Published online: 13 July 2020

(c) Springer-Verlag GmbH Germany, part of Springer Nature 2020

\begin{abstract}
Concerns regarding the comorbidity as a significant risk factor for Coronavirus Disease-2019 (COVID-19), gave rise to an urgent need for studies evaluating patients with chronic conditions such as autoinflammatory diseases (AIDs). We prepared a web-based survey investigating the clinical findings and contact histories among pediatric patients with AIDs. Confirmed COVID-19 cases, patients with contact history and those with symptoms which were highly suggestive of COVID-19 were called via phone or recruited to a video or face to face appointment. Data of AIDs were obtained from their medical records, retrospectively. Laboratory and screening findings were confirmed by our national health registry website. There were 404 patients ( 217 female) eligible for the enrollment. During pandemic, $375(93 \%)$ were on colchicine treatment and $48(11.8 \%)$ were receiving biologic treatment. Twenty-four out of 404 patients were admitted to hospital due to COVID-19 suspicion. Severe acute respiratory syndrome coronavirus-2 (SARS CoV-2) was identified through rhinopharyngeal swabs in seven patients, six of whom were only on colchicine treatment. Only one patient with no finding of any severe respiratory complications was hospitalized. All of seven patients recovered completely. Among patients on biologic drugs, neither a symptom nor a positive polymerase chain reaction test for COVID 19 was detected. In conclusion, pediatric patients with AIDs, those receiving biologic treatment and/or colchicine, may not be at increased risk for neither being infected nor the severe disease course.
\end{abstract}

Keywords SARS-CoV-2 $\cdot$ Autoinflammatory diseases $\cdot$ Colchicine $\cdot$ Covid-19 $\cdot$ Biologic drug

\section{Introduction}

Our paper was published as a pre-print. The link is given below: https://www.researchgate.net/publication/342292166_Evaluation _of_Health_Status_of_Children_with_Autoinflammatory_Disea ses_During_COVID-19_Pandemic.

Ozgur Kasapcopur

ozgurkasapcopur@hotmail.com

Fatih Haslak

drfatihhaslak@gmail.com

Mehmet Yildiz

yildizmehmet@istanbul.edu.tr

Amra Adrovic

amra.adrovic@istanbul.edu.tr

Sezgin Sahin

sezgin@istanbul.edu.tr
A novel coronavirus, named "Severe Acute Respiratory Syndrome Coronavirus 2" (SARS-CoV-2) is responsible for a recently emerged pandemic by causing a disease officially named "Coronavirus Disease-2019" (COVID-19) [1]. At first, the disease appeared as a cluster of pneumonia cases with unknown etiology in China, then spread to other

Oya Koker

oyakoker@hotmail.com

Ayten Aliyeva

aesa099@mail.ru

Kenan Barut

drkenanbarut@hotmail.com

1 Department of Pediatric Rheumatology, Istanbul UniversityCerrahpasa Cerrahpasa Medical School, Istanbul, Turkey 
countries with a route which reminds us the ancient silk road in the first sight, and then finally crossed the ocean. Although China is believed to be the origin of the pandemic, The USA, Brazil, Russia, India, England, Spain, Peru, Italy and Iran are the most affected countries by COVID-19, currently (World Health Organization situation report-151, published on 19 June 2020).

In a study of Chen et al. [2], it was suggested that this novel virus has the propensity to infect elder males, particularly those with an underlying disease. Older age and comorbidities such as hypertension, cardiovascular diseases and diabetes were also found to be risk factors for intensive care unit admission, in a study of Wang et al. [3]. Although fever, dry cough and fatigue are common symptoms, manifestations mimicking rheumatic syndromes such as myalgia, arthralgia, cytopenia, myocarditis and cytokine storm were also reported [4]. While most infected cases are asymptomatic or have mild-moderate symptoms, about \%10-20 of them may experience life-threatening events such as multiorgan dysfunction [5]. However, the disease seems to be milder and less frequent in children compared to adults [6-8]. Despite the infrequently reported pediatric cases during the early days of outbreak, the increasing number of children with confirmed COVID 19 infection has been recently registered [9].

Lombardy region in Italy and Wuhan in China, had the highest number of COVID-19 cases up to date [10,11]. Our pediatric rheumatology department is a referral center in Istanbul, which is the most crowded and the most affected city in Turkey. We have a significant size of registered pediatric patients with autoinflammatory disease (AIDs), including those coming from distinct cities. Since to have comorbidities seems to be a risk factor for infection and possible maybe for worse disease course, it has raised concern that our patients might be more vulnerable to severe COVID-19 compared to general population. Hence, we got hundreds of phone calls from the parents wondering if their children are at increased risk of COVID-19 and questioning the necessity of the cessation of their medication. The parents whose children were on immunosuppressive treatment had more concerns, as expected. Therefore, we aimed to reach as many patients as possible, to learn about their general health conditions and to enlighten them about current outbreak issues.

\section{Methods}

First of all, to conduct this study, we prepared a web-based survey investigating the clinical findings of our patients and the presence of contact with subjects affected by COVID-19 between 11th of March (the day the first case confirmed with COVID-19 in Turkey was reported) and 15th of May 2020. Survey was launched online on 16th of April, 2020. Disease flares, history of contact with confirmed cases, presence of family members with confirmed COVID-19 infection, presence of symptoms resembling COVID-19 such as fever, sore throat, cough, dyspnea, myalgia, diarrhea etc., hospital admission due to suspicion of COVID-19, diagnostic approaches such as polymerase chain reaction (PCR) assay in nasopharyngeal swab and chest computed tomography (CT), prescribed medications and hospitalization histories due to COVID-19, and finally current health conditions were questioned in the survey. Clinical data regarding the AIDs, such as disease onset, complications and current medications were obtained from their medical records, retrospectively. to compare effects of immunosuppression on COVID-19 risk, patients receiving biological treatments were divided into four groups based on the treatment duration: those receiving treatment for less than 1 month, for 1-3 months, for 3-6 months and those receiving biological treatments for longer than 6 months during the pandemic.

Confirmed COVID-19 cases, patients with contact history and patients with symptoms suggestive of COVID-19 were called via phone or recruited to a video or face to face appointment. The communication method was selected according to current curfew conditions which varies day to day and region to region in the country. Laboratory and screening findings were confirmed by our national health registry website.

The study protocol was approved by the Institutional Ethics Committee of our tertiary center (04/16/20-29430533604.01-01-54959). The recommendations of the Declaration of Helsinki for biomedical research involving human subjects were followed. Informed consents were obtained from parents/legal guards of children included in the study.

Children with AIDs aged between 1 and 23 years were included. Patients with an additional rheumatic disease other than AIDs were excluded. To compare the positive PCR test rates for SARS-CoV-2 patients were divided into two groups, those on biologic treatment [anti-interleukin-1 (IL1), anti-interleukin-6 (IL-6) and anti-tumor necrosis factor (TNF) agents] during the pandemic and those who were not treated with biologics during the pandemic.

\section{Statistical analysis}

The statistical analysis was performed using SPSS for Windows, version 21.0 (SPSS Inc., Chicago, IL). The distribution of continuous variables was analyzed by the Kolmogorov-Smirnov test. Categorical variables were expressed as numbers (percentages). Continuous variables were given as mean \pm standard deviation or median (minimum-maximum) according to their distribution. The comparison of the frequencies of the categorical variables between groups was analyzed by Chi-square test or Fisher's-Exact test. Statistical significance was defined as $p<0.05$. 


\section{Results}

\section{Survey results}

Our web-based survey was launched online and circulated to 516 parents of children with AIDs, of whom 484 responded. Among the participants, 41 patients were excluded due to their older age ( $\geq 23$ years old). Another 39 patients were excluded due to presence of another rheumatic disease $(n=12)$, insufficient clinical data $(n=25)$, and denial of the informed consent after filling out the survey $(n=2)$.

Finally, 404 patients (217 female) with a median age of 11.1 years (1.1-22.6) were eligible for the enrollment. Surveys were filled out by mothers $(n=294,72.8 \%)$, fathers $(n=89,22 \%)$, patients themselves $(n=18,4.5 \%)$ and by others $(n=3,0.7 \%)$ (1 brother, 1 aunt and 1 husband). A total of 364 (\%90) patients were diagnosed as Familial Mediterranean Fever (FMF), 14 (\%3.5) as periodic fever aphthous stomatitis pharyngitis and adenitis (PFAPA), $14(\% 3.4)$ as cryopyrin-associated periodic syndromes (CAPS), 4 (\%1) as chronic recurrent multifocal osteomyelitis (CRMO), $3(\% 0.7)$ as deficiency of adenosine deaminase 2 (DADA2), 3 (\%0.7) as Blau syndrome (BS), $1(\% 0.2)$ as tumor necrosis factor receptor associated periodic syndrome (TRAPS) and 1 (\%0.2) as hyperimmunoglobulin D syndrome (HIDS). For each patient, all of the diagnosis mentioned above were confirmed with clinical and genetic findings.

\section{Treatment status of the patients during COVID-19 pandemic}

During pandemic, 375 (93\%) patients (FMF: 364, CAPS: 6, PFAPA: 2, HIDS: 1, TRAPS: 1, DADA2: 1) were on colchicine treatment and $48(11.8 \%)$ were receiving biologic treatments. Of the patients on biologic agents, 35 were on canakinumab (FMF: 21, CAPS: 13, TRAPS: 1). One patient with CAPS was receiving canakinumab for 1-3 months and the other one was receiving for 3-6 months. Three patients with FMF were receiving canakinumab for 1-3 months and one of them was receiving for shorter than 1 month. The rest of patients were receiving canakinumab for longer than 6 months during pandemic), six patients were on etanercept (DADA2: 3 , CRMO: 2, BS: 1 patient). One DADA2 patient was receiving etanercept for 1-3 months, rest of them was receiving etanercept for longer than 6 months. Five patients were on anakinra (FMF: 4, CAPS: 1 patient). Among them, patient with CAPS was receiving anakinra for $1-3$ months. One FMF patient was receiving anakinra for $1-3$ months, 2 of them for 3-6 months, and one FMF patient for longer than 6 months. One patient was on adalimumab (BS; longer than 6 months) and 1 was on tocilizumab (BS; longer than 6 months).

\section{COVID-19 results}

Of the 35 (8.6\%) patients with a confirmed COVID-19 family member, 14 had reported a contact. Additionally, there were 3 other patients with a history of contact with a confirmed COVID-19 patient who is not a family member. Twenty-four of our patients were admitted to hospital due to COVID-19 suspicion and 23 of them (FMF: 20, PFAPA: 1, CAPS: 1, DADA2: 1) were tested using real-time PCR for SARS-CoV-2 (Table 1).

The number of patients with positive PCR result was 7 (FMF: 6, PFAPA: 1); none of them were receiving biologic treatment, while 6 were on colchicine treatment. There were five patients with symptoms (fever, dry cough, sore throat etc.) suggestive of COVID-19: four of them were treated for COVID-19 and were followed-up via outpatient clinic and/or phone. One symptomatic patient was hospitalized for 5 days. Two patients (FMF: 1, PFAPA: 1) were asymptomatic and have not received medication for COVID-19. Chest CT was performed in 10 patients. In two of them, radiological findings were compatible with COVID-19 and both of them had positive PCR test. One patient had ground-glass opacities and air bronchograms and one had consolidation surrounded by the ground-glass opacities (Halo sign) on thorax CT scan (Fig. 1). All of the confirmed cases recovered completely (Table 2).

Two patients receiving biologic treatment had a history of close contact with confirmed COVID-19 family members: one with DADA2 on etanercept and one with CAPS on canakinumab. Both of them were found to be negative for COVID-19 with real-time PCR test. Among the 21 patients who were not on biologic treatment and who were tested for SARS-CoV-2, 7 were found to be positive (FMF: 6, PFAPA: 1). Six of them were on colchicine treatment. Among patients who underwent PCR testing; there was no significant difference between those who were treated with biologic treatment and those who were not, regarding the PCR positivity for COVID $19(p>0.05)$.

\section{Discussion}

Since 11st of March 2020, among 404 AID patients regularly followed-up at our department, 7 of them were diagnosed as COVID-19: 4 of them were in pediatric age (younger than 18 years old) and 3 of them were in young adulthood age. None of them were receiving biologic treatment, six were on colchicine treatment, five were symptomatic. Four patients 
Table 1 Demographic variables, data of chronic health conditions and pandemic period of our patients with autoinflammatory diseases

\begin{tabular}{|c|c|c|c|}
\hline & $\begin{array}{l}\text { Patients not receiving } \\
\text { bDMARDs } \\
(n=356)\end{array}$ & $\begin{array}{l}\text { Patients receiving } \\
\text { bDMARDs } \\
(n=48)\end{array}$ & $p$ \\
\hline Female & $187(52.5 \%)$ & $29(60.4 \%)$ & $>0.05$ \\
\hline Age (years) & $10.9(1.1-22.6)$ & $13(2.3-21.9)$ & $>0.05$ \\
\hline The person who filled out the survey & & & $>0.05$ \\
\hline Mothers & $264(74.2 \%)$ & $30(62.5 \%)$ & \\
\hline Fathers & $73(20.5 \%)$ & $16(33.3 \%)$ & \\
\hline Herself/himself & $16(4.5 \%)$ & $2(4.2 \%)$ & \\
\hline Others & $3(0.8 \%)$ & - & \\
\hline \multicolumn{4}{|l|}{ Diagnosis } \\
\hline FMF & $339(95.2 \%)$ & $25(52.1 \%)$ & \\
\hline PFAPA & $14(3.9 \%)$ & - & \\
\hline CAPS & - & $14(29.2 \%)$ & \\
\hline CRMO & $2(0.6 \%)$ & $2(\% 4.2)$ & \\
\hline DADA2 & - & $3(6.3 \%)$ & \\
\hline Blau syndrome & - & $3(6.3 \%)$ & \\
\hline TRAPS & - & $1(2.1 \%)$ & \\
\hline HIDS & $1(0.3 \%)$ & - & \\
\hline \multicolumn{4}{|l|}{ Treatment they were on } \\
\hline Colchicine & $342(96.1 \%)$ & $34(70.8 \%)$ & \\
\hline Anakinra & - & $5(10.4 \%)$ & \\
\hline$<1$ month & & - & \\
\hline $1-3$ months & & 2 & \\
\hline $3-6$ months & & 2 & \\
\hline$>6$ months & & 1 & \\
\hline Canakinumab & - & $35(72.9 \%)$ & \\
\hline$<1$ month & & 1 & \\
\hline $1-3$ months & & 1 & \\
\hline $3-6$ months & & 4 & \\
\hline$>6$ months & & 29 & \\
\hline Etanercept & - & $6(12.5 \%)$ & \\
\hline$<1$ month & & - & \\
\hline $1-3$ months & & 1 & \\
\hline $3-6$ months & & - & \\
\hline$>6$ months & & 5 & \\
\hline Adalimumab & - & $1(2.1 \%)$ & \\
\hline$<1$ month & & - & \\
\hline $1-3$ months & & - & \\
\hline $3-6$ months & & - & \\
\hline$>6$ months & & 1 & \\
\hline Tocilizumab & - & $1(2.1 \%)$ & \\
\hline$<1$ month & & - & \\
\hline $1-3$ months & & - & \\
\hline $3-6$ months & & - & \\
\hline$>6$ months & & 1 & \\
\hline \multicolumn{4}{|l|}{ SARS CoV-2 PCR test performed } \\
\hline \multicolumn{4}{|l|}{ Contact history } \\
\hline A family member & $12(3.3 \%)$ & $2(4.1 \%)$ & \\
\hline Not a family member & $3(0.9 \%)$ & - & \\
\hline None & $6(16.8 \%)$ & - & \\
\hline
\end{tabular}


Table 1 (continued)

\begin{tabular}{clll}
\hline & $\begin{array}{l}\text { Patients not receiving } \\
\text { bDMARDs } \\
(n=356)\end{array}$ & $\begin{array}{l}\text { Patients receiving } \\
\text { bDMARDs } \\
(n=48)\end{array}$ & $p$ \\
\hline Performed CT & $2(0.55 \%)$ & - & \\
Compatible with COVID-19 & $6(1.65 \%)$ & $2(4.1 \%)$ & $>0.05$ \\
Normal & $7(1.9 \%)$ & - & \\
Positive PCR test & & & \\
\hline
\end{tabular}

DDMARDS biologic disease modifying anti rheumatic drugs, CAPS cryopyrin-associated periodic syndromes, COVID-19 Coronavirus disease-19, CRMO chronic recurrent multifocal osteomyelitis, CT computed tomography, DADA2 deficiency of adenosine Deaminase 2, FMF familial mediterranean fever, HIDS hyperimmunoglobulin D syndrome, PCR polymerase chain reaction, PFAPA periodic fever aphthous stomatitis pharyngitis and adenitis, SARS CoV-2 severe acute respiratory syndrome Coronavirus-2, TRAPS tumor necrosis factor receptor associated periodic syndrome

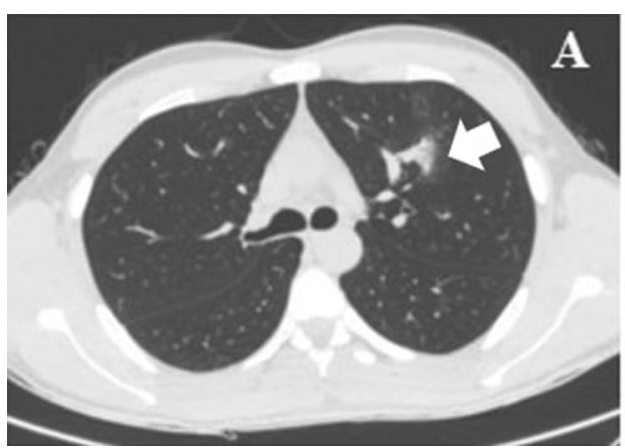

Fig. 1 a On the axial CT image of patient 6, in the upper of left lung, the consolidation surrounded by the ground-glass opacities (Halo sign) is seen. b On the axial CT image of patient 1 , consolidation

were treated and followed-up via outpatient clinic and/or phone, one was hospitalized for 5 days, two were asymptomatic and followed-up without treatment. All of seven patients recovered completely. Although it has been reported in young adulthood previously; to our best knowledge, this is the first report describing frequency, demographic and clinical findings and outcomes of COVID-19 in pediatric patients with AIDs.

Our planet is suffering from SARS CoV-2 since the first couple of days in 2020. World Health Organization (WHO) declared this novel coronavirus outbreak as pandemic on 11 st of March 2020, and the first confirmed case in Turkey was reported on the same day. We have encountered this little-known foe relatively later compared to many other countries. Until that time, many treatment and prevention strategies have been already developed by the health care providers of other countries. Therefore, we were able to make stringent isolation decisions like prompt lockdown and establish our national treatment guidelines which contains hydroxychloroquine and other current available options. Hence, even it is early to mention, numbers of confirmed cases and deaths seem to be low in our country.

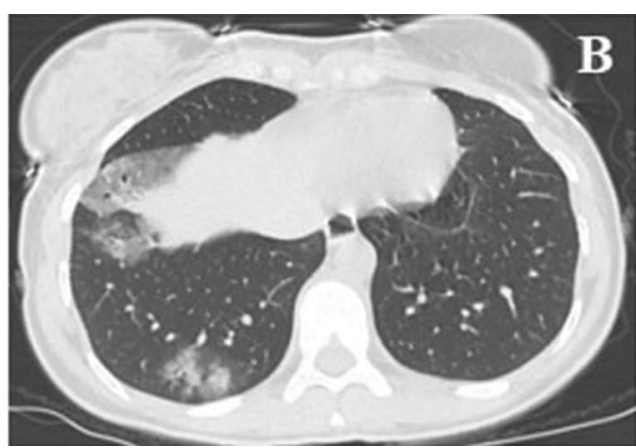

with air bronchograms on the paracardiac area of the right lung, and ground-glass opacities on the posterosuperior subpleural area of the lower lobe of right lung. CT Computed Tomography

However, we have a large number of registered pediatric patients with AIDs. Due to their chronic health conditions and/or immunosuppressive treatment, parents had concerns for their children regarding the current outbreak. Hundreds of phone calls prompted us to perform this study.

Since stringent isolation measures are widely approved and children are infected mostly via exposure to a known adult case, intrafamilial transmissions merit a special approach [12]. In our study, in six of seven patients with positive PCR, source of infection was a family member. Although COVID-19 may lead to serious conditions such as multi-organ dysfunction and even death, it seems that children tend to have a milder disease course [6]. In the study of Dong et al. [13] which consist of the largest number of pediatric patients up to now, $94 \%$ of them were asymptomatic or were presented with mild or moderate disease course. In another report from Wuhan, there were 1391 children who were tested due to contact with confirmed cases. Among them, $12.3 \%$ were SARS-CoV-2 positive and only one patient died [14]. Similarly, to our study group; none of the patients required intensive care and/or ventilation support, even the hospitalized one and all of them recovered 
Table 2 Demographic variables, clinical features, diagnostic and treatment approaches of our COVID-19 patients with autoinflammatory diseases

\begin{tabular}{|c|c|c|c|c|c|c|c|}
\hline & Patient 1 & Patient 2 & Patient 3 & Patient 4 & Patient 5 & Patient 6 & Patient 7 \\
\hline Age (years) & 18.8 & 3.8 & 17.5 & 17.4 & 10.9 & 20.1 & 18.1 \\
\hline Gender & Female & Male & Male & Male & Female & Male & Female \\
\hline Diagnosis & FMF & PFAPA & FMF & FMF & FMF & FMF & FMF \\
\hline $\begin{array}{c}\text { Source of } \\
\text { contact }\end{array}$ & $\begin{array}{l}\text { Father, mother } \\
\text { and two other } \\
\text { siblings }\end{array}$ & $\begin{array}{l}\text { Not a family } \\
\text { member }\end{array}$ & Father, mother & $\begin{array}{l}\text { Father, mother } \\
\text { and one } \\
\text { sibling }\end{array}$ & Father, mother & $\begin{array}{l}\text { Father, mother } \\
\text { and one } \\
\text { sibling }\end{array}$ & Father, mother \\
\hline $\begin{array}{l}\text { Treatments they } \\
\text { were on }\end{array}$ & Colchicine & None & Colchicine & Colchicine & Colchicine & Colchicine & Colchicine \\
\hline $\begin{array}{l}\text { Number of } \\
\text { disease flares } \\
\text { during pan- } \\
\text { demic }\end{array}$ & 6 & 3 & 2 & 1 & 0 & 0 & 0 \\
\hline Symptoms & $\begin{array}{l}\text { Fever, dry } \\
\text { cough, sore } \\
\text { throat, diar- } \\
\text { rhea }\end{array}$ & None & $\begin{array}{l}\text { Fever, dry } \\
\text { cough, sore } \\
\text { throat, dysp- } \\
\text { nea, diarrhea, } \\
\text { myalgia }\end{array}$ & $\begin{array}{l}\text { Fever, dry } \\
\text { cough, diar- } \\
\text { rhea }\end{array}$ & None & $\begin{array}{l}\text { Fever, sore } \\
\text { throat }\end{array}$ & $\begin{array}{l}\text { Fever, dry cough, } \\
\text { sore throat, } \\
\text { diarrhea, } \\
\text { myalgia }\end{array}$ \\
\hline Chest CT & $\begin{array}{l}\text { Air broncho- } \\
\text { grams, } \\
\text { ground-glass } \\
\text { opacities }\end{array}$ & Not performed & Normal & Normal & Normal & Halo sign & Normal \\
\hline Follow-up way & $\begin{array}{l}\text { Outpatient } \\
\text { clinic and/or } \\
\text { via phone }\end{array}$ & $\begin{array}{l}\text { Outpatient } \\
\text { clinic and/or } \\
\text { via phone }\end{array}$ & $\begin{array}{l}\text { Outpatient } \\
\text { clinic and/or } \\
\text { via phone }\end{array}$ & $\begin{array}{l}\text { Outpatient } \\
\text { clinic and/or } \\
\text { via phone }\end{array}$ & $\begin{array}{l}\text { Outpatient } \\
\text { clinic and/or } \\
\text { via phone }\end{array}$ & $\begin{array}{l}\text { Outpatient } \\
\text { clinic and/or } \\
\text { via phone }\end{array}$ & $\begin{array}{l}\text { Hospitalized for } \\
5 \text { days }\end{array}$ \\
\hline $\begin{array}{l}\text { Prescribed } \\
\text { medication }\end{array}$ & $\begin{array}{l}\text { Azithromycin } \\
\text { Oseltamivir } \\
\text { HCQ }\end{array}$ & None & $\begin{array}{l}\text { Azithromycin } \\
\text { Oseltamivir } \\
\text { HCQ }\end{array}$ & $\begin{array}{l}\text { Azithromycin } \\
\text { Oseltamivir } \\
\text { HCQ }\end{array}$ & None & HCQ & $\begin{array}{l}\text { Oseltamivir } \\
\text { HCQ }\end{array}$ \\
\hline $\begin{array}{l}\text { Current situa- } \\
\text { tion }\end{array}$ & Asymptomatic & Asymptomatic & Asymptomatic & Asymptomatic & Asymptomatic & Asymptomatic & Asymptomatic \\
\hline
\end{tabular}

$C T$ computed tomography, $F M F$ familial mediterranean fever, $H C Q$ hydroxychloroquine, $P F A P A$ periodic fever aphthous stomatitis pharyngitis and adenopathy

completely. Some hypothetical ideas emerged regarding the mild disease course in childhood: lower exposure to viruses and air pollution due to being isolated at home mostly thanks to shutting down of the schools, lower smoking rates, higher viral co-infections which may lead to limited replication of SARS CoV-2 and possibly different distribution of ACE2 which acts as a receptor for virus entry into human cells [15].

Although chronic health conditions such as hypertension and diabetes mellitus were found to be risk factors for worse disease course in COVID-19, immunocompromised situations such as rheumatic diseases requiring immunosuppressive treatment were not reported as contributing factor to severe clinical presentation [16]. In a report of Monti et al. [10], 4 of 320 patients with rheumatoid arthritis had confirmed COVID-19 infection and none of them developed serious pulmonary complications.

Despite the limited data, there are some suggestions that patients with AIDs may be vulnerable to infections [17, 18]. On the other hand, it was suggested that people with
$M E F V$ (a gene is associated with FMF) mutations (carrier or patient) may be in a favorable position against a highly contagious diseases; the plague [19].

Based on molecular studies, it has been suggested that enhanced innate immune activation may promote a worse disease outcome in COVID 19 patients [5]. However, most of our patients with AIDs are on colchicine treatment and colchicine is one of the off-label medications used in the treatment of COVID-19, currently [20]. Colchicine is being used in the treatment of FMF since 1972, and it is thought be highly effective on reducing the disease flares and preventing significant complications such as amyloidosis [21]. It is shown in various in vivo and in vitro studies that colchicine has anti-inflammatory and immunomodulatory effects [22]. Based on the mechanism of action of colchicine and hyperinflammatory condition in COVID-19 patients, it was suggested in several reports that colchicine may be beneficial in the treatment of COVID-19 [23-25]. Gandolfini et al. [26] have noted clinical improvement in their COVID19 patient using colchicine. It was recently reported that 
a 36-year-old male with FMF was a confirmed case of COVID-19. Although he had hypertension and obesity as comorbidities, he recovered completely. It was suggested that colchicine could have a protective role on COVID-19 via acting as a NLRP3 inflammasome inhibitor [27]. Moreover, a recently published randomized clinical trial supports the idea that colchicine is a beneficial treatment option in COVID-19 [28]. In our study, among 376 patients on colchicine treatment, only 6 were confirmed COVID-19 cases and all of them recovered completely. To our knowledge, until today, there are no available data describing the COVID-19 frequency among pediatric and/or young adult patients with AIDs.

Among our patients who had a contact history with confirmed COVID-19 cases, one patient with DADA2 (receiving etanercept for 2 months) had a contact with three family members who were confirmed COVID 19 cases (father, brother and grandmother). One patient with CAPS (receiving canakinumab for 2.5 years) had a contact with two family members who were confirmed COVID 19 cases (mother and father). Compared to other coronaviruses (SARS-CoV and MERS-CoV) which caused outbreaks in the past 2 decades, SARS CoV-2 has a higher capability of transmission and infection [29]. Given the immunosuppressive effects of biologic treatment and highly contagious nature of SARS CoV-2, it was interesting that these two patients who were receiving biologic treatment and had close contact histories were completely asymptomatic, with negative PCR tests. Consistent with our results, in a study from a liver transplantation unit from Italy, none of the patients who received immunosuppressive treatment developed lung disease, even some were confirmed COVID-19 cases [30]. Similarly, Conticini et al. [31] reported that there were two patients with confirmed COVID-19 in their rheumatology department. One patient was a 50-year-old woman affected by rheumatoid arthritis, receiving rituximab and the other one was an 87-year-old woman affected by giant cell arteritis, receiving tocilizumab; both of them discharged and then remained asymptomatic.

Although serious concerns for patients on immunosuppressive treatment seems reasonable at first, there is no sufficient data in the literature supporting such an attitude. In a study of Gianfrancesco et al. [32], 600 confirmed COVID-19 cases with rheumatic diseases were evaluated and to receive biologic treatment was not found to be a risk factor for being hospitalized. Filocamo et al. [33] included pediatric rheumatic patients on biological treatment and none of them were diagnosed as COVID-19.

Since it is known that main mechanism of lung injury occurs due to a hyperinflammatory situation resembling cytokine storm syndrome, studies investigating the therapeutic effects of biologic agents on COVID-19 were launched [34]. In hospitalized patients with COVID-19, serum IL-6 levels were found to be elevated. Consequently, the tocilizumab (an anti-IL-6 agent) was found to be effective in the treatment of COVID-19 patients with cytokine storm syndrome [35]. Anakinra, an anti-IL-1 agent, has a favorable effect on patients with hyperinflammation, as well [36]. It was shown in a report from France that anakinra provided clinical improvement in eight of nine patients with COVID-19 [37]. Moreover, as it is known that SARS CoV-2 might induce TNF-alpha converting enzyme for penetration into human cells, a trial evaluating the effects of anti-TNF agents on COVID-19 has been registered in China, currently [38]. Therefore, this relative favorable position of children receiving biologic treatment may be attributed to their inability to develop hyperinflammatory conditions resembling cytokine storm syndrome, due to their insufficient immune system.

Since a certain percentage of COVID 19 cases may be misdiagnosed by PCR test, many centers in our country perform chest CT routinely, particularly in symptomatic cases. In our study, chest CT was performed in six of seven patients with confirmed COVID-19. There were two patients with CT findings compatible with COVID19. One of these two patients had ground-glass opacities, the most common CT finding in COVID-19 patients [2, $3]$. The other one had consolidation surrounded by the ground-glass opacities (Halo sign). Although halo sign is a rare CT sign in adults, Xia et al. [9] suggest that it is a typical sign in pediatric patients.

The main limitation of our study is that there were no included otherwise healthy patients who were admitted to hospital due to suspicion of COVID-19 as a control group. Additionally, we had a short observation period due to relatively later onset of COVID 19 outbreak compared to many other countries.

In conclusion, to our best knowledge, this is the first study reporting the pediatric COVID-19 patients with AIDs. Our preliminary experience shows that pediatric patients with AIDs, even if they receive biologic treatment, are not at increased risk for neither being infected with SARS CoV-2 nor the severe disease course. There are some recently published data suggesting protective role of biological treatments and colchicine on COVID 19. Moreover, autoinflammatory conditions such as FMF possible protects COVID 19 patients from the poor outcome. Bearing on mind the increased risk for disease flares during the infections among AID patients, we, rheumatologists, should warn our patients not to withdraw their medication, unless they are advised to do so.

Author contributions FH, MY, AA, SS, OK were responsible for data collection and analysis. FH, MY, AA contributed to the writing of the manuscript. OK, AA, KB, OK reviewed and revised the manuscript. 
Funding The authors have not declared a specific grant for this research from any funding agency in the public, commercial or not-for-profit sectors.

Data sharing statement All data relevant to the study are included in the article.

\section{Compliance with ethical standards}

Conflict of interest Authors declare that there is no conflict of interest.

Ethics approval The study was approved by Istanbul University-Cerrahpasa Institutional Review Board (29430533-604.01-01-54959).

Informed consent A written informed consent was obtained from all the participants included in this study and no identifying information of any participant was included in this paper.

\section{References}

1. Haşlak F, Yıldız M, Adrovic A, Barut K, Kasapçopur Ö (2020) Childhood rheumatic diseases and COVID-19 pandemic: an intriguing linkage and a new horizon. Balkan Med J. https://doi. org/10.4274/balkanmedj.galenos.2020.2020.4.43

2. Chen N, Zhou M, Dong X, Qu J, Gong F, Han Y, Qiu Y, Wang J, Liu Y, Wei Y (2020) Epidemiological and clinical characteristics of 99 cases of 2019 novel coronavirus pneumonia in Wuhan, China: a descriptive study. The Lancet 395(10223):507-513

3. Wang D, Hu B, Hu C, Zhu F, Liu X, Zhang J, Wang B, Xiang H, Cheng Z, Xiong Y (2020) Clinical characteristics of 138 hospitalized patients with 2019 novel coronavirus-infected pneumonia in Wuhan China. JAMA 323(11):1061-1069

4. Misra DP, Agarwal V, Gasparyan AY, Zimba O (2020) Rheumatologists' perspective on coronavirus disease 19 (COVID-19) and potential therapeutic targets. Clin Rheumatol 39(7):2055-2062. https://doi.org/10.1007/s10067-020-05073-9

5. Hedrich CM (2020) COVID-19-considerations for the paediatric rheumatologist. Clin Immunol (Orlando, FL) 214:108420. https:// doi.org/10.1016/j.clim.2020.108420

6. Ludvigsson JF (2020) Systematic review of COVID-19 in children shows milder cases and a better prognosis than adults. Acta Paediatr 109(6):1088-1095

7. Gasparyan AY, Misra DP, Yessirkepov M, Zimba O (2020) Perspectives of immune therapy in Coronavirus disease 2019. J Korean Med Sci 35(18):e176-e176. https://doi.org/10.3346/ jkms.2020.35.e176

8. Korkmaz MF, Türe E, Dorum BA, Kılıç ZB (2020) The epidemiological and clinical characteristics of 81 children with COVID19 in a pandemic hospital in Turkey: an observational cohort study. J Korean Med Sci 35(25):e236. https://doi.org/10.3346/ jkms.2020.35.e236

9. Xia W, Shao J, Guo Y, Peng X, Li Z, Hu D (2020) Clinical and CT features in pediatric patients with COVID-19 infection: different points from adults. Pediatr Pulmonol 55(5):1169-1174

10. Monti S, Balduzzi S, Delvino P, Bellis E, Quadrelli VS, Montecucco C (2020) Clinical course of COVID-19 in a series of patients with chronic arthritis treated with immunosuppressive targeted therapies. Ann Rheum Dis 79(5):667-668

11. Lei S, Jiang F, Su W, Chen C, Chen J, Mei W, Zhan L-Y, Jia Y, Zhang L, Liu D, Xia Z-Y, Xia Z (2020) Clinical characteristics and outcomes of patients undergoing surgeries during the incubation period of COVID-19 infection. EClinicalMedicine 21:100331-100331. https://doi.org/10.1016/j.eclinm.2020.100331

12. Cai J, Xu J, Lin D, Yang Z, Xu L, Qu Z, Zhang Y, Zhang H, Jia R, Liu P, Wang X, Ge Y, Xia A, Tian H, Chang H, Wang C, Li J, Wang J, Zeng M (2020) A case series of children with 2019 novel coronavirus infection: clinical and epidemiological features. Clin Infect Dis. https://doi.org/10.1093/cid/ciaa198

13. Dong Y, Mo X, Hu Y, Qi X, Jiang F, Jiang Z, Tong S (2020) Epidemiological characteristics of 2143 pediatric patients with 2019 coronavirus disease in China. Pediatrics. https://doi.org/10.1542/ peds.2020-0702

14. Lu X, Zhang L, Du H, Zhang J, Li YY, Qu J, Zhang W, Wang Y, Bao S, Li Y (2020) SARS-CoV-2 infection in children. N Engl J Med 382(17):1663-1665

15. Balasubramanian S, Rao NM, Goenka A, Roderick M, Ramanan AV (2020) Coronavirus disease 2019 (COVID-19) in children-what we know so far and what we do not. Indian Pediatr 57(5):435-442. https://doi.org/10.1007/s13312-020-1819-5

16. Ferro F, Elefante E, Baldini C, Bartoloni E, Puxeddu I, Talarico R, Mosca M, Bombardieri S (2020) COVID-19: the new challenge for rheumatologists. Clin Exp Rheumatol 38(2):175-180

17. Society TGR, of Rheumatologists PA (2020) Recommendations regarding COVID19 infection in rheumatic patients in Greece. Mediterr J Rheumatol 31(1):6

18. Pham-Huy A (2019) Inborn errors of immunity: the missing link in infectious diseases susceptibility. Off J Assoc Med Microbiol Infect Dis Can 4(2):51-54

19. Batu ED, Özen S (2020) Implications of COVID-19 in pediatric rheumatology. Rheumatol Int. https://doi.org/10.1007/s0029 6-020-04612-6

20. Bilbul M, Paparone P, Kim AM, Mutalik S, Ernst CL (2020) Psychopharmacology of COVID-19. Psychosomatics. https://doi. org/10.1016/j.psym.2020.05.006

21. La Regina M, Ben-Chetrit E, Gasparyan AY, Livneh A, Ozdogan H, Manna R (2013) Current trends in colchicine treatment in familial Mediterranean fever. Clin Exp Rheumatol 31(3 Suppl 77):41-46

22. Gasparyan AY, Ayvazyan L, Yessirkepov M, Kitas GD (2015) Colchicine as an anti-inflammatory and cardioprotective agent. Expert Opin Drug Metab Toxicol 11(11):1781-1794. https://doi. org/10.1517/17425255.2015.1076391

23. Piantoni S, Colombo E, Airò P, Tincani A, Brucato A, Franceschini F, Andreoli L, Furloni R, Scarsi M (2020) The rationale for the use of colchicine in COVID-19: comments on the letter Cumhur Cure $\mathrm{M}$ et al. Clin Rheumatol. https://doi.org/10.1007/ s10067-020-05232-y

24. Parra-Medina R, Sarmiento-Monroy JC, Rojas-Villarraga A, Garavito E, Montealegre-Gómez G, Gómez-López A (2020) Colchicine as a possible therapeutic option in COVID-19 infection. Clin Rheumatol. https://doi.org/10.1007/s10067-020-05247-5

25. Piantoni S, Patroni A, Toniati P, Furloni R, Franceschini F, Andreoli L, Scarsi M (2020) Why not to use colchicine in COVID19? An oldanti-inflammatory drug for a novel auto-inflammatory disease. Rheumatol (Oxford, Engl) 59(7):1769-1770. https://doi. org/10.1093/rheumatology/keaa217

26. Gandolfini I, Delsante M, Fiaccadori E, Zaza G, Manenti L, Degli Antoni A, Peruzzi L, Riella LV, Cravedi P, Maggiore U (2020) COVID-19 in kidney transplant recipients. Am J Transplant. https ://doi.org/10.1111/ajt.15891

27. Kobak S (2020) COVID-19 infection in a patient with FMF: does colchicine have a protective effect? Ann Rheum Dis. https://doi. org/10.1136/annrheumdis-2020-217882

28. Deftereos SG, Giannopoulos G, Vrachatis DA, Siasos GD, Giotaki SG, Gargalianos P, Metallidis S, Sianos G, Baltagiannis S, Panagopoulos P, Dolianitis K, Randou E, Syrigos K, Kotanidou A, Koulouris NG, Milionis H, Sipsas N, Gogos C, Tsoukalas 
G, Olympios CD, Tsagalou E, Migdalis I, Gerakari S, Angelidis C, Alexopoulos D, Davlouros P, Hahalis G, Kanonidis I, Katritsis D, Kolettis T, Manolis AS, Michalis L, Naka KK, Pyrgakis VN, Toutouzas KP, Triposkiadis F, Tsioufis K, Vavouranakis E, Martinèz-Dolz L, Reimers B, Stefanini GG, Cleman M, Goudevenos J, Tsiodras S, Tousoulis D, Iliodromitis E, Mehran R, Dangas G, Stefanadis C (2020) Effect of colchicine vs standard care on cardiac and inflammatory biomarkers and clinical outcomes in patients hospitalized with Coronavirus disease 2019: the GRECCO-19 randomized clinical trial. JAMA Netw Open 3(6):e2013136. https://doi.org/10.1001/jamanetworkopen .2020 .13136

29. Pedersen SF, Ho YC (2020) SARS-CoV-2: a storm is raging. J Clin Invest 130(5):2202-2205. https://doi.org/10.1172/jci137647

30. D'Antiga L (2020) Coronaviruses and immunosuppressed patients: the facts during the third epidemic. Liver Transplant 26(6):832-834. https://doi.org/10.1002/lt.25756

31. Conticini E, Bargagli E, Bardelli M, Rana GD, Baldi C, Cameli P, Gentileschi S, Bennett D, Falsetti P, Lanzarone N, Bellisai F, Barreca C, D'Alessandro R, Cantarini L, Frediani B (2020) COVID19 pneumonia in a large cohort of patients treated with biological and targeted synthetic antirheumatic drugs. Ann Rheum Dis. https ://doi.org/10.1136/annrheumdis-2020-217681

32. Gianfrancesco MA, Hyrich KL, Gossec L, Strangfeld A, Carmona L, Mateus EF, Sufka P, Grainger R, Wallace Z, Bhana S, Sirotich E, Liew J, Hausmann JS, Costello W, Robinson P, Machado PM, Yazdany J (2020) Rheumatic disease and COVID-19: initial data from the COVID-19 Global Rheumatology Alliance provider registries. Lancet Rheumatol 2(5):e250-253. https://doi.org/10.1016/ s2665-9913(20)30095-3
33. Filocamo G, Minoia F, Carbogno S, Costi S, Romano M, Cimaz R (2020) Absence of severe complications from SARS-CoV-2 infection in children with rheumatic diseases treated with biologic drugs. J Rheumatol. https://doi.org/10.3899/jrheum.200483

34. Sarzi-Puttini P, Giorgi V, Sirotti S, Marotto D, Ardizzone S, Rizzardini G, Antinori S, Galli M (2020) COVID-19, cytokines and immunosuppression: what can we learn from severe acute respiratory syndrome? Clin Exp Rheumatol 38(2):337-342

35. Cron RQ, Chatham WW (2020) The rheumatologist's role in COVID-19. J Rheumatol 47(5):639-642. https://doi.org/10.3899/ jrheum.200334

36. Mehta P, McAuley DF, Brown M, Sanchez E, Tattersall RS, Manson JJ (2020) COVID-19: consider cytokine storm syndromes and immunosuppression. Lancet 395(10229):1033-1034

37. Aouba A, Baldolli A, Geffray L, Verdon R, Bergot E, MartinSilva N, Justet A (2020) Targeting the inflammatory cascade with anakinra in moderate to severe COVID-19 pneumonia: case series. Ann Rheum Dis. https://doi.org/10.1136/annrheumdis-2020217706

38. Favalli EG, Ingegnoli F, De Lucia O, Cincinelli G, Cimaz R, Caporali R (2020) COVID-19 infection and rheumatoid arthritis: faraway, so close! Autoimmun Rev 19(5):102523. https://doi. org/10.1016/j.autrev.2020.102523

Publisher's Note Springer Nature remains neutral with regard to jurisdictional claims in published maps and institutional affiliations. 